\title{
Memahami dan Mengukur Toleransi dari Perspektif Psikologi Sosial
}

\author{
Supriyanto ${ }^{1 *}$ \\ ${ }^{1 .}$ Program Studi Psikologi, Universitas Pembangunan Jaya \\ *E-mail: supriyanto@upj.ac.id
}

\begin{abstract}
Abstrak
Toleransi dibutuhkan dalam suatu masyarakat yang komposisinya beragam, mulai dari keberagaman etnis, suku, budaya, bahasa dan agama. Perilaku toleran dan sikap menghargai perbedaan juga dibutuhkan ketika kita menjalin relasi dengan bangsa-bangsa lain serta sudah memutuskan untuk terlibat dalam tatanan global. Toleransi merupakan penerimaan atas hal-hal yang tidak disetujui atau tidak disukai agar kita dapat berhubungan dan berinteraksi lebih baik dengan orang lain. Artikel ini ditujukan untuk mengkaji toleransi dari sudut pandang Psikologi Sosial mulai dari sejarah, pengertian dan konsep tentang toleransi; kondisi dan karakteristik toleransi; serta dimensi-dimensi dari toleransi. Artikel ini juga ditujukan untuk melakukan studi awal dalam rangka mengembangkan skala yang mengukur konstruk toleransi. Skala toleransi disusun berdasarkan Index of Tolerance yang dibuat oleh Soldatova, dkk. Hasil penelitian menunjukkan reliabilitas skala kurang baik $(0,55)$ dan terdapat 8 buah item yang tidak valid untuk mengukur konstruk toleransi. Diperlukan perbaikan dan penyesuaian agar skala ini bisa digunakan untuk memahami dan mengukur toleransi di Indonesia.
\end{abstract}

\section{Keywords: Toleransi; Psikologi Sosial; Intergroup Relations}

\section{Mukadimah}

Akhir-akhir ini, kasus yang bertentangan dengan semangat toleransi kembali terjadi di berbagai belahan dunia. Pada pertengahan bulan Agustus 2017, di kota Charlottesville, Negara Bagian Virginia, Amerika Serikat pecah kerusuhan antar dua kelompok yang mengakibatkan tiga orang meninggal dunia dan puluhan lainnya luka-luka. Kerusuhan tersebut dipicu oleh demonstrasi kelompok Neo-Nazi/nasionalis kulit putih yang hendak menegaskan supremasi dan dominasi ras kulit putih di Amerika. Kelompok ini umumnya membenci kelompok minoritas dari sisi etnis, ras dan agama (Kompas, 2017). Dalam kasus British Exit (Brexit), faktor utama yang mendasari keputusan warga Britania Raya untuk keluar dari keanggotaan Uni Eropa yaitu adanya prasangka (prejudice) terhadap imigran-imigran dari luar Inggris (Johnston, 2017). Sementara itu di Australia, seperti yang dilaporkan oleh Soutphommasane (2017) dari media Sdyney Morning Herald, beberapa universitas dan sekolah telah ditulisi dengan pesan-pesan yang menyuarakan propaganda supremasi kulit putih yang ditujukan kepada kelompok-kelompok Yahudi, Muslim dan warga Asia.

Sama halnya dengan fenomena yang terjadi di Amerika, Inggris dan Australia, kasus-kasus intoleransi juga banyak ditemui di Indonesia. Laporan dari Komnas HAM menunjukkan bahwa dari tahun ke tahun kasus intoleransi di Indonesia cenderung mengalami peningkatan. Pada tahun 2014, Komnas HAM mencatat 74 kasus intoleransi yang dilaporkan ke pos pengaduan Desk KBB. Di tahun 2015, jumlah pengaduan meningkat menjadi 87 kasus. Sedangkan pada tahun 2016, kasus intoleransi yang dilaporkan lebih besar dibandingkan tahun sebelumnya, yaitu hampir mencapai 100 kasus. Kasus-kasus intoleransi di Indonesia yang bertentangan dengan Hak Asasi Manusia tersebut muncul dalam beragam bentuk, antara lain: melarang aktivitas keagamaan, merusak rumah ibadah, diskriminasi atas dasar keyakinan 
atau agama, tindakan intimidasi dan pemaksaan keyakinan (Putra, 2017).

Toleransi dibutuhkan agar dapat hidup bersama secara harmonis. Menurut Verkuyten dan Yogesswaran (2017), peningkatan keragaman secara global baik dalam aspek budaya dan agama menuntut adanya toleransi terhadap kelompokkelompok yang berbeda untuk mencapai keharmonisan antar kelompok. Toleransi akan memberikan beberapa konsekuensi positif bagi kelompok minoritas, antara lain: memungkinkan mereka untuk mengekspresikan identitas kulturalnya, memberikan akses terhadap sumber daya dan hak dan melindungi mereka dari tindakantindakan kekerasan. Toleransi juga akan memberi warga minoritas kebebasan dan hak untuk mendefinisikan dan mengembangkan jalan hidup mereka (Verkuyten dan Yogesswaran, 2017). Sementara bila toleransi absen maka nilai-nilai keragaman, kesetaraan dan perdamaian akan menghilang dalam kehidupan komunitas (Doorn, 2012). Lunturnya pemahaman mutual menyebabkan rusaknya integritas relasi sosial yang kemudian dapat mengarah ke agresi (Marchenoka, Chehlova \& Vogule, 2014).

Konsep toleransi telah muncul sejak beberapa abad yang lalu. Menurut Walzer (dalam Verkuyten dan Yogesswaran, 2017), secara historis konsep toleransi merupakan usaha untuk mengatasi dampak bahaya dan kekerasan dari konflik agama. Sementara Goudsblom (dalam Doorn, 2012) menyatakan bahwa jauh sebelum term toleransi digunakan dalam kajian-kajian ilmiah, toleransi merujuk pada aktivitas perlawanan aktual terhadap tirani dan represi. Pada abad 17 istilah toleransi ditulis di pamflet-pamflet untuk memprotes inkuisisi dan persekusi dari Gereja. Selama abad 18 M, toleransi tidak hanya alat untuk memperjuangkan kebebasan dari agama, namun juga untuk memperjuangkan tatanan kehidupan sosial yang sekuler yang menjadi cikal bakal tegaknya demokrasi liberal di Eropa yang kita kenal saat ini (Goudsblom, dalam Doorn, 2012). Pada masa sekarang, term toleransi tidak lagi dimaknai sebagai toleransi dalam konteks agama saja, namun meluas yang meliputi orientasi politik, keragaman etnis dan ras, isu gender, LGBT, euthanasia serta aborsi (Doorn, 2012).
Toleransi dapat dimaknai dalam berbagai cara, seperti menghargai dan merayakan perbedaan, sikap positif umum (general positive attitude) terhadap kelompok lain, tidak adanya prasangka, serta menerima sesuatu yang tidak disetujui atau yang diprasangkakan (Robinson dkk., dalam Verkuyten \& Slooter, 2007). APA (dalam Nizah, Jawan, Singh \& Samsu, 2015) mendefinisikan toleransi sebagai penerimaan seseorang terhadap orang lain yang tindakan, keyakinan, kemampuan fisik, agama, adat-istiadat, etnisitas, dan kewarganegaraannya berbeda dengan dirinya sendiri. Dalam kajian Psikologi Sosial, toleransi seringkali disamakan dengan konsep nonjudgmental, keterbukaan (open), menghargai keragaman atau dipandang sebagai sikap positif umum (general positive attitude) terhadap kelompok lain (Verkuyten dan Yogesswaran, 2017). Bervariasinya makna dari toleransi dapat menyulitkan dalam usaha mengukur, mengintepretasikan, menentukan anteseden dan melaksanakan penelitian-penelitian empiris tentang toleransi (Gibson, dalam Doorn, 2012). Lebih lanjut, Door (2012) menyarankan dalam melakukan riset tentang toleransi, hendaknya peneliti memahami secara jelas term yang digunakan, jernih dalam memilih satu definisi dibandingkan definisi yang lain, selalu berusaha menyelaraskan antara definsi dan bagaimana definisi toleransi dioperasionalkan dalam pengukuran serta memahami konteks sosial dimana toleransi dimaknai.

Pada penelitian ini, peneliti menggunakan definisi toleransi berdasarkan pendapat dari Vogt (dalam Doorn, 2012), yaitu penerimaan atas hal-hal yang tidak disetujui atau tidak disukai agar kita dapat berhubungan dan berinteraksi lebih baik dengan orang lain. Secara garis besar, Vogt (dalam Doorn, 2012) menggolongkan toleransi dalam tiga tipe, yaitu: 1) toleransi politik (political tolerance), yang berarti toleransi terhadap aksi-aksi/tindakan di ruang publik seperti memberikan pidato, demonstrasi, menyebarkan brosur/leaflet, mengorganisasikan pertemuan dan rapat, dan lain sebagainya. Toleransi tipe ini concern dengan dukungan terhadap kebebasan masyarakat sipil, terutama dukungan kepada kelompok-kelompok yang tidak disukai atau tidak popular; 2) toleransi moral (moral tolerance), yaitu toleransi terhadap tindakan-tindakan/aksi yang dilakukan di ruang privat, yang biasanya tipe ini bersifat kontorversial, 
seperti seksualitas, pornografi, homoseksual dan aborsi; dan 3) toleransi sosial (social tolerance), merujuk pada penerimaan terhadap karakteristikkarakteristik orang yang diperoleh sejak lahir atau diperoleh sejak awal proses sosialisasi. Contoh toleransi tipe ini yaitu warna kulit, bahasa, dll.

Menurut Sullivan dkk., Vogt (dalam Doorn, 2012), terdapat prasyarat dan kondisi dimana toleransi dapat eksis/ada. Pertama, harus ada kondisi ketidaksetujuan, ketidaksukaan. Toleransi mensyaratkan adanya oposisi, ketidaksetujuan dan keberatan dari satu pihak ke pihak yang lain. Kedua, toleransi mengacu pada ketidaksetujuan, ketidaksukaan yang sifatnya penting bagi orang. Bila seseorang tidak menganggap penting suatu perbedaan, maka mereka tidak peduli dengan perbedaan tersebut. Dua karakteristik/kondisi di atas sangat krusial untuk memahami makna dari toleransi. Meskipun bidang Psikologi Sosial telah lama mengkaji tentang konsekuensi-konsekuensi hubungan antar kelompok (seperti stereotipe, prasangka, diskriminasi), namun masih sedikit teori yang sistematis dan studi empiris yang mengkaji toleransi dari perspektif dari Psikologi Sosial (Verkuyten \& Yogeswaran, 2017). Selain untuk menjelaskan konsep-konsep tentang toleransi, artikel ini juga ditujukan untuk menyusun sebuah skala untuk mengukur toleransi berdasarkan skala the Index of Tolerance yang dikembangkan oleh Soldatova, dkk (dalam Marchenoka, Chehlova \& Vogule, 2014; Banshchikova, Solomonov, \& Fomina, 2015). Lebih khusus lagi penelitian ini hendak menguji apakah skala yang dibuat memiliki konsistensi internal yang tinggi dan valid untuk mengukur tingkat toleransi.

\section{Metode}

Penelitian dilakukan melalui pendekatan kuantitatif dengan menggunakan kuesioner sebagai instrumen penelitian. Subjek penelitian dipilih dengan menggunakan teknik purposif sampling dengan karakater: jenis kelamin laki-laki dan perempuan, latar belakang pendididikan mulai dari SMP dan berusia dari 17 tahun. Alat ukur disusun dalam bentuk skala Likert yang menyediakan enam alternatif jawaban. Kuesioner toleransi ini dibuat berdasarkan kuesioner the Index of Tolerance yang dibuat oleh Soldatova (dalam Marchenoka,
Chehlova \& Vogule, 2014; Banshchikova, Solomonov \& Fomina, 2015; Pasichnyk \& Balashow, 2016). Skala toleransi ini terdiri dari 22 item yang mengukur tiga jenis toleransi, yaitu toleransi etnis ( 7 item), toleransi sosial (8 item) dan toleransi sebagai trait kepribadian (7 item). Respon jawaban dinilai $1-6$ dan penilaian untuk item unfavorable dibalik. Skor 22-60 menunjukkan tingkat toleransi yang rendah; skor 61-99 berarti tingkat toleransi sedang, sementara tingkat toleransi individu dinilai tinggi bila rentang skor berada pada 100-132 (Marchenoka, Chehlova \& Vogule, 2014). Menurut Khitruk \& Ulianova (2012), tingkat toleransi rendah mengindikasikan individu memiliki trait yang intoleran dan mengekspresikannya terhadap orang lain dan lingkungan sekitar; tidak mampu menerima sudut pandang, opini, dan gagasan yang berbeda serta mengekspresikan pandangan yang chauvinism. Tingkat intoransi sedang mencerminkan kombinasi trait yang toleran dan intoleran dalam diri individu, tergantung pada situasi yang dihadapi (orang dengan toleransi sedang menunjukkan toleran di situasi tertentu, namun tidak toleran di situasi yang lain. Tingkat toleransi tinggi menunjukkan trait toleransi dan tindakan diekspresikan secara jelas jelas, toleran terhadap orang lain yang berbeda dan memilki beliefs yang berbeda, empati serta simpati. Tabel 1 menjelaskan masing-masing tipe toleransi/sub skala, pengertian dan komposisi item.

Data penelitian diperoleh melalui penyebaran kuesioner di area Jakarta, Bogor, Depok, Tangerang dan Bekasi (Jabodetabek). Jumlah responden yang terlibat dalam penelitian ini sejumlah 99 orang. Data demografis responden ditujukkan pada tabel 2.

Uji realibilitas pada skala toleransi ini menggunakan koefisien Alpha Cronbach dan diperoleh hasil sebesar 0,55. Nilai koefisien reliabilitas tersebut tergolong kurang baik, karena menurut Kaplan dan Sacuzzo (2005), batas koefisien reliabilitas yang baik untuk sebuah penelitian adalah 0.6-0.8. Sedangkan hasil uji validitas item menunjukkan terdapat 8 buah item yang tidak valid untuk mengukur toleransi karena nila $r$ hasil perhitungan item tersebut lebih kecil dari pada $r$ tabel. Tabel 3 menunjukkan 8 item yang tidak valid. 
Tabel 1.

Dimensi, pengertian dan sebaran item indeks toleransi

\begin{tabular}{|c|c|c|c|c|}
\hline \multirow{2}{*}{ No } & \multirow{2}{*}{$\begin{array}{l}\text { Sub } \\
\text { Skala }\end{array}$} & \multirow{2}{*}{ Pengertian } & \multicolumn{2}{|c|}{ Item } \\
\hline & & & Favorable & Unfavorable \\
\hline 1. & $\begin{array}{l}\text { Toleransi } \\
\text { Etnis }\end{array}$ & $\begin{array}{l}\text { Merepresentasikan sikap individu terhadap anggota kelompok etnis lain dan } \\
\text { karakteristik-karakteristik mereka dalam konteks interaksi antar budaya. } \\
\text { Toleransi ini di karakteristikkan dengan kemauan untuk mengakui dan } \\
\text { menerima keberadaan budaya, tradisi, nilai, tingkah laku dari etnis lain. }\end{array}$ & $\begin{array}{l}5,9,11,18, \\
21\end{array}$ & 3,14 \\
\hline 2. & $\begin{array}{l}\text { Toleransi } \\
\text { Sosial }\end{array}$ & $\begin{array}{l}\text { Merepresentasikan ekspresi dan sikap individu terhadap berbagai kelompok } \\
\text { sosial lain (kelompok minoritas, kelainan mental, orang miskin) serta sikap } \\
\text { individu terhadap proses sosial tertentu. Toleransi ini menunjukkan bahwa } \\
\text { pengakuan pada hak-hak kelompok sosial lain yang ada di masyarakat } \\
\text { disebabkan oleh kematangan sosial dan psikologis dari individu. }\end{array}$ & $13,19,20$ & $\begin{array}{l}1,4,7,10, \\
16\end{array}$ \\
\hline 3. & $\begin{array}{l}\text { Toleransi } \\
\text { Sebagai } \\
\text { Trait } \\
\text { Kepribad } \\
\text { ian }\end{array}$ & $\begin{array}{l}\text { Ciri kepribadian, beliefs, sikap yang menentukan relasi individu dengan } \\
\text { dunia sekitarnya. } \\
\text { Sub skala ini memungkinkan untuk mengeksplorasi kualitas dan beliefs } \\
\text { individu yang akan menentukan sikap mereka terhadap lingkungan sosial- } \\
\text { budaya. }\end{array}$ & 12,15 & $\begin{array}{l}2,6,8,17 \\
22\end{array}$ \\
\hline
\end{tabular}

\section{Results}

Hasil penelitian menunjukkan bahwa koefisien reliabilitas skala toleransi ini tergolong kurang baik dan terdapat 8 buah item yang tidak valid. Terdapat beberapa aspek yang menyebabkan indeks reliabilitas dan item pada skala ini kurang baik, antara lain:

1. Jumlah subyek penelitian yang kurang dan tidak merepresentasikan populasi. Seperti terlihat di tabel 2, jumlah subyek penelitian sebanyak 99 responden. Dari total responden tersebut, subyek penelitian mayoritas berdomisili di Tangerang Selatan $(53,5 \%)$ dan berusia antara 16-20 tahun $(52,5 \%)$.

2. Terdapat item kuesioner yang ambigu dan kurang bisa dipahami oleh subyek seperti item nomor 8 (Saya menjadi jengkel bila ada gangguan dan kekacauan), nomor 11 (Budaya dan tradisi suku saya tidak lebih baik dari pada budaya dan suku tradisi yang lain), nomor 19 (Di media massa, semua pendapat dan opini bisa dimuat dan ditayangkan).
3. Pengembangan item untuk mengukur toleransi perlu diselaraskan sesuai dengan sudut pandang dan konteks masyarakat Indonesia. Skala asli dari the Index of Tolerance ini dibuat oleh Soldatova dalam bahasa Rusia. Skala ini juga diadaptasi dan digunakan di negara-negara Eropa Timur seperti Belarusia (Khitruk \& Ulianova, 2012), Ukraina (Pasichnyk \& Balashow, 2016), Latvia (Marchenoka, Chehlova \& Vogule, 2014) yang dahulu merupakan negara sekutu Rusia. Sementara penulis - yang tidak bisa berbahasa Rusia - dalam mengadopsi skala ini mengacu pada teori dan literatur yang ditulis oleh peneliti lain dalam bahasa Inggris. Adanya kesenjangan konteks budaya dan bahasa ini diduga berkontribusi terhadap item-item yang tidak valid dan indeks reliabilitas yang kurang baik. Menurut Doorn (2012), konteks sosial-budaya harus dipertimbangkan dalam mengoperasionalkan konstruk toleransi. Selain itu, riset mengenai toleransi sebaiknya juga tidak hanya fokus pada level individual saja, namun juga melibatkan aspekaspek yang bersifat meso dan makro. 
Tabel 2.

Data demografis responden penelitian

\begin{tabular}{|c|c|c|}
\hline \multirow[t]{2}{*}{ Jenis Kelamin } & Laki-Laki & $25,3 \%$ \\
\hline & Perempuan & $74,7 \%$ \\
\hline \multirow[t]{5}{*}{ Usia } & $16-20$ tahun & $52,5 \%$ \\
\hline & $21-25$ tahun & $13,1 \%$ \\
\hline & $26-30$ tahun & $10,1 \&$ \\
\hline & 31 - 35 tahun & $11,1 \%$ \\
\hline & $>35$ tahun & $13,2 \%$ \\
\hline \multirow[t]{5}{*}{ Suku } & Jawa & $32,3 \%$ \\
\hline & Batak & $11,1 \%$ \\
\hline & Sunda & $11,1 \%$ \\
\hline & Betawi & $10,1 \%$ \\
\hline & Lain-lain & $35,4 \%$ \\
\hline \multirow[t]{3}{*}{ Agama } & Islam & $78,8 \%$ \\
\hline & Kristen & $17,2 \%$ \\
\hline & Lain-lain & $4 \%$ \\
\hline \multirow{4}{*}{$\begin{array}{l}\text { Tingkat } \\
\text { Pendidikan }\end{array}$} & SMA & $62,6 \%$ \\
\hline & S1 & $23,2 \%$ \\
\hline & $\mathrm{S} 2$ & $13,1 \%$ \\
\hline & S3 & $1 \%$ \\
\hline \multirow[t]{4}{*}{ Domisili } & Tangerang Selatan & $53,5 \%$ \\
\hline & Jakarta & $28,3 \%$ \\
\hline & Tangerang & $12,1 \%$ \\
\hline & Lain-lain & $6,1 \%$ \\
\hline
\end{tabular}

Tabel 3.

Item skala toleransi yang tidak valid

\begin{tabular}{lll} 
Sub skala & Item & Keterangan \\
\hline Toleransi etnis & $5,9,11$ & Tidak valid \\
\hline Toleransi sosial & 7,16 & Tidak valid \\
\hline $\begin{array}{l}\text { Toleransi sebagai trait } \\
\text { kepribadian }\end{array}$ & $2,8,15$ & Tidak valid \\
\hline
\end{tabular}

\section{Kesimpulan.}

Penelitian ini dilakukan sebagai langkah awal untuk mengembangkan skala toleransi. Hasil penelitian menunjukkan indeks reliabilitas skala masih kurang baik dan terdapat 8 item yang kurang valid untuk mengukur konstruk toleransi. Perlu dilakukan beberapa perbaikan dan penyesuaian agar skala ini bisa digunakan untuk memahami dan mengukur toleransi di Indonesia. Beberapa saran untuk penelitian lanjutan yang diajukan oleh peneliti antara lain: memperbanyak jumlah subyek, memilih karakteristik subyek yang sesuai dan proporsional, merevisi item yang kurang baik, melakukan wawancara elisitasi mengenai konsep toleransi kepada beberapa responden, dan bila perlu mengelaborasi teori-teori tentang toleransi yang sesuai dengan konteks sosial-budaya masyarakat Indonesia.

\section{Referensi}

Banshchikova, T., Solomonov, V. \& Fomina, E. (2015). Attitudes and tolerance in the structure of individual readiness for intercultural interaction. Procedia Social and Behavioral Sciences, 214 (2015): 916 924.

Doorn, M.V. (2012). Tolerance. Sociopedia.isa. 1-15. DOI: 10.1177/2056846012121. 1.

Johnston, I. (2017, Juni). Brexit: Anti-Immigrant Prejudice Major Factor In Deciding Vote, Study Finds. Diakses pada tanggal 7 Agustus 2017 dari

http://www.independent.co.uk/news/uk/politics/brexit-racismimmigrant-prejudice-major-factor-leave-vote-winstudy-a7801676.html

Kaplan, R.M dan Saccuzzo, D.P. (2005). Psychological Testing Principles, Application and Issue. Sixth Edition. USA: Wadsworth

KhitrukV.V. \& Ulianova, O.A. (2012). Inclusive Tolerance As A Basis Of Professional Competence Of Prospective Teachers. Problems Of Psychology In The 21st Century, Vol. 43: $21-32$.

Kompas. (2017, Agustus). Trump Kecam Insiden di Virginia, Tak Singgung "Supremasi Kulit Putih". Diakses pada tanggal 7 Agustus 2017 dari

http://internasional.kompas.com/read/2017/08/13/08234111/tr ump-kecam-insiden-di-virginia-tak-singgungsupremasi-kulit-putih-

Marchenoka, M., Chehlova, Z. \& Vogule, G. (2014). Development of a tolerant personality as an objective need of the modern civil society in Cunningham, P. \& Fretwel, N. (eds). Innovative Practice and Research Trends in Identity, Citizenship and Education. London: CiCe, pp. 361 - 374.

Nizah, M.A.M., Jawan, J.A., Singh, S.S. \& Samsu, K.H.K. (2015). framing ethnic tolerance, political tolerance and voting behaviour. Mediterranean Journal of Social Sciences, 6( 4): $365-373$.

Pasichnyk, I.D. \& Balashow, E.M. (2016). Psychological Peculiarities Of Tolerance Of Ukrainian And Polish Students: A Comparative Analysis. Problems Of Psychology In The 21st Century, Vol. 10 (1): 39 49. 
Putra., L.M. (2017, Januari). Catatan Komnas HAM, Kasus Intoleransi Meningkat Setiap Tahun [Online]. Diakses pada tanggal 7 Agustus 2017 dari http://nasional.kompas.com/read/2017/01/05/18280 081/catatan.komnas.ham.kasus.intoleransi.meningk at.setiap.tahun

Soutphommasane, T. (2017, Agustus). How to Respond to The Worldwide Upswing In Racism. Diakses pada tanggal 7 Agustus 2017 dari http://www.smh.com.au/comment/how-to-respond-to-theworldwide-upswing-in-racism-20170822gylcyt.html

Verkuyten, M. \& Yogesswaran, K. (2017). The social psychology of intergroup toleration: a roadmap for theory and research. Personality and Social Psychology Review, 21(1): 72-96.

Verkuyten, M. \& Slooter, L. (2007). Tolerance of muslim beliefs and practices: Age related differences and context effects. International Journal of Behavioral Development, 31 (5), 467-477.. 